\title{
REFLEXÕES SOBRE AS DIFICULDADES DA IMPLEMENTAÇÃO DA PARTICIPAÇÃO INSTITUCIONAL NO BRASIL
}

\author{
Wagner de Melo Romão*
}

\begin{abstract}
Resumo: A Constituição Federal de 1988 sugeriu que as políticas públicas por ela emanadas deveriam ser realizadas em regime de gestão compartilhada, isto é, com a participação da sociedade. A partir daí, conselhos, conferências, audiências públicas e outras instâncias de participação, que já ocorriam ocasionalmente em determinadas localidades e setores, multiplicaram-se como elementos de chancela para a elaboração e tomada de decisão em políticas públicas. Há, entretanto, algum mal estar com a pouca efetividade destas instâncias e mecanismos de participação institucional. De certo modo para diminuir esta percepção, o governo federal buscou, nos últimos anos, avaliar o funcionamento destas instâncias e mecanismos e terminou por propor, sem sucesso, a criação de um Sistema e uma Política Nacional de Participação Social. Sugere-se que as abordagens sobre implementação de políticas públicas podem ser férteis para uma compreensão mais acurada do tema.
\end{abstract}

Palavras-chave: Participação. Políticas Públicas. Implementação. Política Nacional de Participação Social.

Reflections on the implementation's difficulties of institutional participation in Brazil

Abstract: The 1988 Federal Constitution issued that the public policies should be carried out in shared management, that is, with society participation. In the following years after its proclamation instances as councils, conferences, public hearings and others - those already were occasional in certain localities and governments sectors - multiplied as seal elements for the formulation and decision making process in public policy. However, the effectiveness of these bodies and institutional participation mechanisms has been questioning and creating some discontent. The federal government in the recent years, trying to reduce this perception, promoted an evaluation of these instances and mechanisms and proposed, unsuccessfully, the creation of a system and a National Policy for Social Participation. This article aims to show the necessity of a broader focus over the institutional participation difficulties seeking a more refined look at the public policies implementation studies.

* Departamento de Ciência Política - Unicamp. Email: wromao@unicamp.br. Recebido em: 17/12/2014 Aceito em: 31/07/2015 
$|36|$

Reflexões sobre as dificuldades de implementação...

Keywords: Participation. Public Policy. Implementation. National Policy for Social Participation.

Reflexiones sobre las dificultades de aplicación de la participación institucional en Brasil

Resumen: La Constitución Federal de 1988 sugirió que las políticas públicas emitidas por ella deben llevarse a cabo en régimen de gestión compartida, es decir, con la participación de la sociedad. A partir de entonces, el asesoramiento, conferencias, audiencias públicas y otras instancias de participación, que ya ocurrieron ocasionalmente en ciertos lugares y sectores, se han multiplicado como elementos de sellado para la preparación y toma de decisiones en las políticas públicas. Hay, sin embargo, un cierto malestar con poca efectividad de estos órganos y mecanismos de participación institucional. Como forma de reducir esta percepción, el gobierno federal buscó, en los últimos años, evaluar el funcionamiento de estos órganos y mecanismos y terminó proponiendo, sin éxito, la creación de un sistema y una Política Nacional de Participación Social. Se sugiere que los abordajes sobre la implementación de las políticas públicas pueden ser fértiles para una comprensión más precisa de la materia. Palabras-clave: Participación. Políticas Publicas. Implementación. Política Nacional de Participación Social.

\section{1 - Apresentação}

Pode-se dizer que desde os primeiros trabalhos de pesquisa sobre os conselhos, orçamento participativo e outras instâncias e mecanismos de participação institucional (IMPI), a literatura acadêmica já apontava seus limites. De maneira geral, eles eram interpretados como fruto da inserção das IMPI em contextos políticos permeados por uma cultura política "autoritária" e "clientelista" advinda, sobretudo, de atores estatais ou relacionados aos partidos políticos tradicionais (DAGNINO, 2002; AVRITZER, NAVARRO, 2003; NEVES, 2008), ou mesmo dos partidos de esquerda, como já indicava Moura (1993) em trabalho pioneiro sobre o orçamento participativo de Porto Alegre. Já era possível perceber, a partir de pesquisas qualitativas realizadas na década de 1990, calcadas especialmente em entrevistas com conselheiros da sociedade civil, a ausência de "eficácia deliberativa" (TATAGIBA, 2002) nos conselhos. Porém, esse tema somente passará a ser tratado como o foco principal e impulsionador de 
pesquisas a partir de estudos mais recentes, surgidos já no final da década de 2000, quando aflora com urgência a questão da efetividade.

Não se trata de mero acaso que esta guinada na literatura para o campo de estudos sobre a efetividade das IMPI tenha se colocado no contexto de um governo liderado pelo Partido dos Trabalhadores - o governo federal, na segunda metade do governo Lula e governo Dilma Rousseff. É verdade que os conselhos de políticas públicas datam do primeiro período de Getúlio Vargas na presidência da República. E também é necessário considerar que o governo Fernando Henrique Cardoso ampliou o rol de temas de conferências de políticas públicas e criou novos conselhos nacionais/federais. No entanto, isto ocorreu de maneira modesta naquele período. Foi mesmo no governo Lula que se multiplicaram as conferências e os novos conselhos de políticas públicas. Se, por um lado, é inegável que as quase sete dezenas de conferências do período Lula devem ser interpretadas como um processo de mobilização e consulta popular jamais ocorrido - assim como a proliferação de conselhos -, por outro lado, isto ocorreu sem que, ao menos nos primeiros momentos, se perguntasse o significado destes processos para a produção de políticas públicas. Fazer uma conferência nacional ou criar um conselho nacional estava referido à necessidade de se democratizar o Estado, ouvir os movimentos sociais, oxigenar a Esplanada dos Ministérios. No entanto, logo setores dos movimentos sociais e das organizações da sociedade civil, por um lado, e os próprios agentes governamentais, mais ou menos comprometidos com o projeto político do governo petista, por outro lado, iriam se perguntar: de que nos adianta participar de conferências e conselhos? De que nos adianta tanto gasto de recursos públicos para a organização de conferências e conselhos? Estes espaços de participação realmente influenciam a ação do governo?

O presente texto pretende sustentar a necessidade de que, a partir dos dilemas sobre a questão da efetividade da participação institucional, se estabeleça uma agenda de pesquisa que considere o tema da implementação das IMPI. Deste modo, será possível 
produzir conhecimento novo, que leve em conta os embates internos aos governos para a criação, manutenção e desenvolvimento de espaços e mecanismos institucionais de participação.

Esta proposta esta desenvolvida aqui apenas de maneira preliminar e exploratória. O texto está composto, além dessa introdução, por quatro partes. Na sequência, apresento como a questão da gestão compartilhada e da participação da sociedade nas políticas públicas apareceu na Constituição Federal de 1988 e se estruturou, na década de 1990 e 2000, como parte do arcabouço da ação governamental no Brasil. No tópico seguinte, aponto parte das deficiências das IMPI no contexto nacional e as dificuldades de sua implementação. Na terceira parte, mostro como, a partir das perguntas sobre a efetividade, o governo federal buscou operar no campo da melhora das condições de implementação das IMPI. Ou seja, trata-se de mostrar como o governo federal gerou uma nova agenda político-institucional sobre a participação institucional, em busca de melhorar sua efetividade, que necessariamente passa pela capacidade indutora da União em desenvolver parâmetros para a implementação da participação institucional. O artigo se finaliza com o apontamento de uma possível agenda de pesquisas sobre o tema, que deve ter como centro a literatura sobre implementação de políticas públicas.

\section{2 - A Constituição de 1988 e o papel da participação institucional na descentralização de políticas públicas}

A Constituição de 1988 sugeriu que as políticas públicas por ela emanadas deveriam ser realizadas em regime de gestão compartilhada, isto é, com a participação da sociedade. O próprio processo político da Assembleia Nacional Constituinte se deu de forma a incorporar elementos de participação direta da sociedade civil em sua formulação, de forma ainda não vista no país. A veiculação de informativos em cadeia de televisão e rádio, a possibilidade da indicação de emendas populares pela sociedade, 
a ativa participação em audiências públicas, enfim, todo o debate público gerado tornou o período constituinte um momento de elaboração democrática dos rumos do país (LESSA, 2008).

Entretanto, especificamente no que se refere à indicação literal sobre a participação da sociedade, o texto constitucional é bastante sucinto e, com o significado que aqui nos interessa, o termo "participação" se mostra pouco na Constituição. Vejamos como ele aparece, artigo por artigo.

É prevista, no artigo $8^{\circ}$ e no $10^{\circ}$, a participação dos sindicatos nas negociações trabalhistas e em colegiados de órgãos públicos de seus interesses; no artigo 187, é prevista a participação de produtores e trabalhadores rurais na elaboração da "política agrícola"; no artigo 194, sobre a seguridade social, o inciso VII prevê o "caráter democrático e descentralizado da gestão administrativa, com a participação da comunidade, em especial de trabalhadores, empresários e aposentados"; no artigo 198, sobre as ações e serviços de saúde, o inciso III prevê que uma das diretrizes do sistema único a ser criado é a "participação da comunidade"; no artigo 204, sobre a área de assistência social, a segunda diretriz (sendo que a primeira, como também no caso da saúde, é a descentralização administrativa) indica a "participação da população, por meio de organizações representativas, na formulação das políticas e no controle das ações em todos os níveis". Se ampliarmos um pouco o escopo, incorporando o termo "gestão democrática", ele aparece no artigo 206, sobre os princípios do ensino, inciso VI, sendo um deles a "gestão democrática do ensino público, na forma da lei".

É de se notar como a ideia de participação está sempre relacionada às políticas públicas. Política agrícola, seguridade social, saúde, assistência social e a gestão democrática da educação, sem se esquecer da menção à necessidade de participação dos sindicatos nas negociações trabalhistas. Há também, sobretudo nos casos da saúde e da assistência social, forte proximidade entre a participação e o indicativo da descentralização das políticas. Ou seja, a Constituição, embora não tenha sido eloquente, vinculou diretamente a participação à mudança pretendida naquele 
momento histórico, em que as unidades subnacionais - estados e municípios - se colocavam com força na arena política da Nova República (ABRUCIO, 1994).

A partir dessa determinação geral, quase abstrata, presente na nova Constituição, o Estado brasileiro foi gerando, ao longo da década de 1990, formas de colocar em prática a participação institucionalizada. Em realidade, o que ocorreu foi o aumento da incidência e da periodicidade de realização de formasjá existentes de participação de forma mais ou menos desordenada. O constituinte, apesar do célebre parágrafo $1^{\underline{0}}$ do artigo $1^{\underline{0}}$ da Constituição, não estabeleceu regras para a atuação "direta" do cidadão nos assuntos públicos, ao menos de maneira próxima ao que fez com relação ao sistema político-partidário-eleitoral tradicional. Assim, embora esteja de acordo com o espírito que parece emanar em alguns pontos bastante específicos da Constituição, a participação institucional carece, até nossos dias, de uma normativa que possa estabelecer suas exatas funções no processo de governo brasileiro.

Certamente em função desta ausência de princípio norteador sobre como se dariam formas alternativas de participação política para além da tradicional eleição de representantes, a participação institucional no Brasil foi tomando a forma do que já era consuetudinário no setor de políticas públicas mais avançado à época, especialmente na construção de uma alternativa ao modelo centralizado da ditadura de 1964. Embora não previsto na Constituição, foi por meio de duas instâncias de participação previstas nos institutos do Sistema Único de Saúde, pela Lei 8080/90 e, em seguida, por sua complementação na Lei no8142/90, que se foi gradativamente tomando forma a gestão compartilhada no contexto dos setores de políticas. As leis do SUS, especialmente a última lei citada, adotam conselhos e conferências como os instrumentos pelos quais a sociedade local érepresentada na tomada de decisão sobre as políticas públicas. O princípio da participação comunitária presente no projeto de saúde pública e coletiva que está nas origens do SUS, levado a cabo pelo movimento sanitarista desde os anos 1970 (DOWBOR, 2009), foi o elemento mais maduro 
da ideia de que a descentralização das políticas públicas prevista na Constituição deveria se dar com participação social.

Assim, aos poucos os instrumentos de participação existentes foram se metamorfoseando e crescendo em número, nos municípios, estados e no nível nacional, de maneira a serem elementos estruturadores da descentralização de políticas públicas em turno desde a década de 1980. No entanto, as expectativas de determinados setores da sociedade civil e mesmo de burocratas e membros de governos sobre a participação institucional foi se mostrando, ao longo do tempo, em seu processo de implementação, como algo em geral pouco producente.

\section{3 - Dificuldades na implementação da participação institucional}

Neste tópico, procuro brevemente desenvolver três ideias relativas às dificuldades da implementação da participação institucional no contexto brasileiro. Inicio pelo tema da difícil "autonomia" da sociedade civil na relação com os governos, que legitimaria toda e qualquer iniciativa de gestão compartilhada das políticas públicas. Em seguida, aponto as insuficiências da capacidade do Estado de estruturar a participação institucional no âmbito governamental. Por fim, sugiro a necessidade da articulação dos mecanismos de participação institucional no âmbito da federação.

A indicação, em alguns artigos da CF-88, da necessidade de participação da sociedade/comunidade nas deliberações sobre e na formulação de políticas públicas - e mesmo na ideia de gestão compartilhada entre Estado e sociedade presente no que viria a ser o Sistema Único de Saúde e o Sistema Único de Assistência Social, por exemplo - tem como elemento implícito a ideia de que a sociedade é um ente à parte do Estado, à parte dos governos, mas que deve, legitimamente, atuar em conjunto com eles na formulação e deliberação sobre políticas públicas e, ademais, no próprio controle das ações do Estado. 
Tal situação de separação entre Estado e sociedade foi reforçada pela literatura sobre o tema que se desenvolveu no Brasil nos anos 1990. Pressupunha-se que, no ambiente democrático que aos poucos se firmava, a sociedade iria atuar de maneira não só a afirmar sua (nova) autonomia - uma vez que se tratava de uma sociedade civil renovada pelas movimentações autonomistas ocorridas no final da década de 1970 e início da década de 1980 mas também a modificar a estrutura de um Estado autoritário, que passara mais de vinte anos em um regime de exceção, impondo uma nova cultura política democrática no país (AVRITZER, 1996).

A normatividade da lei e do texto acadêmico, por um longo período, fez com que ficasse obnubilada aos governos, à academia estudiosa do tema e à própria sociedade civil, a fragilidade da ideia de uma separação forte entre o Estado - com suas instituições políticas, o sistema político em geral, os partidos políticos, os agentes governamentais - e a sociedade civil.

É algo raro a existência de uma representação da sociedade civil politicamente neutra. Ocorre que, no contato com os meios políticos, e mesmo partidários, os agentes vinculados a organizações da sociedade civil, movimentos sociais, igrejas, sindicatos etc. necessariamente se colocam em posição de disputa política, de maneira a sustentar seus interesses e valores que, por sua vez, clivam também a sociedade política (TATAGIBA, BLINKSTAD, 2011; TATAGIBA, SERAFIM, ABERS, 2014; ROMÃO, 2014). A ideia de uma sociedade civil apartada da sociedade política está genuinamente relacionada a uma oposição entre elas, numa visão elitista de controle de poder por aqueles que o manejam.

Embora esta visão possa contrariar o discurso de uma sociedade civil idealizada, autônoma e pretensamente desinteressada - e, neste sentido, desfavorecer certo uso político que se faz da participação institucional como espaço híbrido de encontro entre governo e sociedade civil - não considero que ela inviabilize ou faça diminuir a importância da participação em conselhos, conferências e outras formas e mecanismos. Se funcionarem bem, estes espaços podem ser instâncias mediadoras dos conflitos sobre posições políticas e ideológicas existentes nos 
processos deliberativos sobre políticas públicas, e que não se dão necessariamente no confronto entre governos e sociedade civil, mas nas diversas clivagens no interior da sociedade civil e dos governos, que promovem parcerias e acordos mútuos entre agentes societários e governamentais. Algo como uma arena especial de disputa política, mediada por regras e por algum nível de racionalidade - ao gosto da literatura da democracia deliberativa - em que se possa buscar formular consensos em torno das ações em políticas públicas. E de maneira, também, a tornar estas disputas menos confinadas em instituições políticas mais afeitas às práticas tradicionais de barganha, como os parlamentos. Ou seja: uma virtual "falta de autonomia" da sociedade civil não pode ser sustentáculo para que se diminua o valor democrático das IMPI.

A esta visão, agrego um segundo ponto: qual a capacidade dos governos em propiciar a existência de IMPI em que seja possível ocorrer condições ótimas de atuação dos representantes da sociedade civil e dos governos, com os objetivos indicados acima?

De maneira geral, as críticas que são feitas ao Estado e/ou governos com relação às suas relações com a sociedade civil e suas representações, giram em torno à denúncia da "cooptação", especialmente, mas não só, dos movimentos sociais. Esta é a outra da ideia de autonomia, que critiquei acima. Não obstante, para se conseguir avançar no debate sobre o papel e a responsabilidade dos governos com relação aos espaços de participação institucional, é preciso ir além desta chave. Aqui, surge o tema da capacidade do Estado em tornar os espaços de participação institucional minimamente aptos à contribuição para a elaboração de políticas públicas.

A principal variável relevante neste quesito é o setor de políticas públicas (saúde, educação, cultura, desenvolvimento urbano, habitação, meio ambiente, assistência social etc.) e sua tradição em processos participativos para formulação e deliberação. Enquanto algumas áreas apresentam um histórico de organização em torno de conselhos e conferências, outros setores são infensos à participação institucional, construídos que foram em processos 
muito internos ao Estado. Ou seja, trata-se de considerar a trajetória de relação entre agentes da sociedade civil e agentes estatais - e os espaços e mecanismos pelos quais ocorre esta relação - quando se for considerar a importância relativa da participação institucional na estruturação de políticas. As resistências a ela serão tão mais fortes quanto menos aqueles agentes estiverem habituados a processos participativos na execução de seu trabalho ou do lobby por suas demandas.

O dilema, neste caso, é o seguinte: por um lado, há a necessidade de se padronizar procedimentos participativos no sentido de provocar neles a ampliação e aperfeiçoamento dos mecanismos de debate, de disputa de ideias e de tomada de decisões coletivas. Mas, por outro lado, quanto mais esta padronização violar princípios básicos e muitas vezes implícitos de funcionamento dos fatores de influência para a formulação e deliberação sobre políticas públicas, aumenta a probabilidade de que as novas IMPI sejam pouco efetivas.

Assim, a preocupação expressada por alguns autores sobre uma "burocratização da participação" (VRIES, 2000), não pode levar a que se suspendam as iniciativas pela publicização dos processos decisórios e por uma sensível diminuição dos acordos de bastidores em que as partes menos potentes - em geral localizadas na sociedade civil em seu embate com agentes do poder ou do mercado - permaneçam como coadjuvantes no jogo político.

De maneira geral, a não ser nos governos mais estruturados, não há setor específico destinado a atuar na padronização de rotinas e procedimentos relativos aos espaços e mecanismos de participação institucional. Cada setor estabelece sua própria maneira de dar conta de suas estruturas de participação, sejam conferências, conselhos, audiências públicas e outros. Deste modo, pouco e muito lentamente se evolui em termos de metodologias de participação, técnicas de interlocução e debate, ponderação de demandas e resoluções. Trata-se de outra dimensão da questão da efetividade destes espaços. Não exatamente dos resultados em termos de políticas públicas - a questão de fundo deste debate mas de funcionamento mesmo da participação institucional. 
Por último, um tema essencial quando se discute implementação de políticas públicas em contextos federativos: a necessidade de articulação entre as estruturas de participação institucional seja quanto à sua normatividade, seja quanto à coerência das decisões tomadas nestas instâncias, seja ainda quanto à importância de se considerar os aspectos diferenciais de estruturas locais, estaduais e nacionais de participação.

Caminhamos muito pouco neste quesito. Em ambientes federativos democráticos, em que as legitimidades de prefeitos, governadores e presidentes são fundamentadas pelo voto e cuja autonomia decisória é garantida pela Constituição - especialmente no caso brasileiro em que o município é ente federativo -, qualquer processo de articulação de políticas - ou de descentralização, como aponta Arretche (1999) - é bastante difícil e complexo, na comparação com Estados mais centralizados ou ditatoriais. Países da América Latina têm buscado estabelecer parâmetros nacionais de participação social, por meio de legislação ordinária ou de seus textos constitucionais ${ }^{1}$. No caso brasileiro, o desafio parece ser maior, uma vez que nossas IMPI, como os conselhos, as conferências e mesmo as audiências públicas estão bastante ancorados em legislação específica dos setores de políticas públicas ou então são regulamentados por legislação de menor grau, como decretos, portarias ou resoluções ${ }^{2}$.

\footnotetext{
${ }^{1}$ Chile, Lei n. 20.500, sobre associações e participação cidadã na gestão pública, 2011; Uruguai, Lei n. 18.567, de descentralização política e participação cidadã; Equador, Lei orgânica de participação cidadã, 2011; Nicarágua, Lei n. 475, de participação cidadã, 2003; Peru, Lei n. 26300, dos direitos de participação e controle cidadãos, 1994 e Lei. n. 28.056, Lei marco do orçamento participativo, 2003; Bolívia, Lei n. 341, de participação e controle social.

${ }^{2}$ Não me referirei aqui a outros conteúdos possíveis para o estabelecimento de uma lei nacional de participação cidadã ou algo do gênero, como regras claras e mais avançadas para referendos, plebiscitos, revogação de mandatos, controle social, governo aberto, que certamente deveriam compor o cenário ideal de debates sobre uma reforma mais ampla no sistema político brasileiro.
}

Idéias - Rev. Inst. Filos. Ciênc. Hum. UNICAMP, v.6, n.2, p. 35-58, jul/dez. 2015 
Trata-se, portanto, de um terreno pantanoso. Embora a participação institucional venha se tornando uma realidade no Estado brasileiro desde a década de 1990, não há ainda avanço político no sentido de uma valorização estrutural em nosso sistema político. Pior que isso, nos últimos anos, dada a forte polarização política que grassa no país, tem-se partidarizado a participação institucional, inviabilizando a construção de consensos em torno de uma proposta de marco nacional sobre o tema.

No próximo tópico, veremos como as iniciativas recentes do governo federal no campo da implementação da participação institucional tem se desenvolvido no período recente.

\section{4 - Avaliar a participação institucional e estabelecer uma Política Nacional de Participação Social}

A rápida disseminação de conselhos e também de processos periódicos de participação - as conferências - se deu pari passu à disseminação das políticas públicas federativas, em forma de sistema (como o SUS, o SUAS e outras formas menos desenvolvidas de sistemas de políticas públicas). Este avanço da participação institucional, no entanto, gerou dois eixos de queixas e críticas, formuladas pelos próprios atores nesses processos, ambos relacionados à questão da efetividade do aparato de participação. Pelo lado dos atores da sociedade civil, inclusive os mais próximos do que poderíamos indicar como um campo de apoio ao governo petista, surgiram dúvidas sobre qual, de fato, seria o poder decisório dos conselhos e das conferências. Valeria a pena investir tempo e preparo das principais lideranças dos movimentos para a participação nos conselhos nacionais? Valeria a pena se mobilizar as bases para participar das etapas municipais e estaduais das conferências? ${ }^{3}$

Por outro lado, os custos envolvidos na organização das reuniões dos conselhos e nas etapas das conferências (tanto os

${ }^{3}$ Nesse sentido, ver Szwako (2012). 
custos orçamentários como os operacionais e do aproveitamento dos recursos humanos) passaram a ser questionados no interior do próprio governo, especialmente pelas alas menos afeitas a uma trajetória de militância em movimentos sociais ${ }^{4}$.

No âmbito do governo federal, no contexto do final do segundo mandato de Luis Inácio Lula da Silva, percepções como as indicadas acima e, adicionalmente, a compreensão de uma grande desarticulação entre as IMPI fez fortalecer entre ativistas próximos ao PT e também no interior do governo, especialmente na SG-PR, a necessidade de um dispositivo legislativo que pudesse consolidar e organizar de forma aprimorada tais espaços e mecanismos. Neste momento, segundo Pedro Pontual

\begin{abstract}
Falava-se muito em políticas de Estado e não apenas em políticas de governo. Até surgiu aquela ideia, parece que do próprio Lula: do mesmo modo que tínhamos a Consolidação das Leis do Trabalho (CLT), era preciso ter a "consolidação das leis sociais" que institucionalizasse os vários programas e políticas sociais que foram implementados durante os dois mandatos do seu governo. Nesse momento, na Secretaria-Geral e nas redes que tinham mais diálogos com a Secretaria, começa a se dizer o seguinte: vamos aproveitar essa ideia e também buscar uma institucionalização das políticas de participação social. Então, tem-se aí as primeiras discussões sobre a ideia da criação de um sistema de participação social. (Gurza Lavalle, Szwako, 2014, p. 98)
\end{abstract}

No entanto, avaliou-se que não seria o momento de que essa CLT social e também o eventual sistema de participação social viessem à tona, dada toda a disputa eleitoral do período final do governo. A ideia é retomada no início do governo Dilma Rousseff, no âmbito da Secretaria Nacional de Articulação Social, órgão da SG-PR. No entanto, novamente segundo relato de Pedro Pontual,

${ }^{4}$ Sobre a visão dos burocratas sobre as conferências, ver Souza e Pires (2012).

Idéias - Rev. Inst. Filos. Ciênc. Hum. UNICAMP, v.6, n.2, p. 35-58, jul/dez. 2015 
havia certa incongruência de posições no interior do governo sobre os fatores de sucesso ou fracasso dos modelos de participação, especialmente das conferências, e a necessidade de estudos mais rigorosos sobre as IMPI.

A gente encontrou diagnósticos muito contraditórios quando a gente chegou. Para dar um exemplo: havia pessoas que participaram de conferências durante os oito anos de governo Lula com avaliações superpositivas delas e, de outro lado, outros diagnósticos eram bastante céticos, querendo rediscutir a efetividade desses espaços: "Será que eles já não estão se esgotando? Será que já não produziram o que deviam produzir? Bateu no teto?". (idem, p. 99).

Neste contexto, na necessidade da construção de diagnósticos mais precisos sobre a efetividade - e até mesmo o lugar político das conferências, conselhos e outros espaços e mecanismos - houve um encontro de expectativas e ações entre a própria SG-PR e o Instituto de Pesquisa Econômica Aplicada (IPEA), especialmente sua Diretoria de Estudos e Políticas do Estado, das Instituições e da Democracia (DIEST), criada em março de 2010.

A partir do primeiro mandato de Lula, com Márcio Pochmann na presidência da instituição, o IPEA passa por um processo de remodelagem e de ampliação de suas funções. São criadas novas diretorias e setores de pesquisa, entre elas a DIEST, na qual se consolidou, no início do governo Dilma Rousseff, a linha de trabalho Democracia e Participação Social (DPS) ${ }^{5}$.

O conjunto de pesquisadores ancorado na DPS passou a realizar trabalhos de pesquisa e de assessoria ao governo federal,

5 Entrevista com o então diretor da DIEST, Alexandre de Ávila Gomide, à revista Desafios do Desenvolvimento, Edição 69, Ano 8, de 21/11/2011. As outras linhas de pesquisa são Estado e Desenvolvimento; e Justiça e Segurança Pública. http://www.ipea.gov.br/desafios/index. php?option=com_content\&view=article\&id=2654: catid=28\&Itemid=23. Acesso em 10/10/2013. 
sobretudo à Secretaria Nacional de Articulação Social (SNAS), parte da SG-PR. Uma das principais iniciativas do grupo foi o projeto Institucionalização da Participação Social do Brasil, que se iniciou também em 2010. No contexto desse projeto, foram produzidos livros, artigos, relatórios, textos para discussão e notas técnicas sobre conselhos, conferências, ouvidorias, audiências públicas e outros temas relativos às interfaces socioestatais. Esta equipe realizou pesquisas e interlocução com um sem número de ministérios ou secretarias, mas especialmente com a equipe da SNAS, subsidiando as demandas relacionadas à proposição da Política (PNPS) e do Sistema Nacional de Participação Social (SNPS).

Além da atuação no interior do governo, a entrada do IPEA no circuito de pesquisas sobre participação institucional deu novo vigor a esse campo de conhecimento em ciência política no Brasil. Constituiu-se um novo polo de produção e de articulação de pesquisadores, com olhar focado no tema da efetividade das chamadas instituições participativas ${ }^{6}$. A existência deste grupo de pesquisas adjunto ao governo federal propiciou que o pensamento sobre a participação institucional pudesse ser instrumentalizado para o aperfeiçoamento desses organismos, em um contexto de pouca aplicabilidade do acúmulo de conhecimento acadêmico. De um lado, já não cabiam mais análises de cunho normativolaudatório, hegemônicas em um período no qual o orçamento participativo, os novos conselhos e conferências eram vistos como espaços de invenção democrática protegidos da política partidária e dominados por uma sociedade civil pura, sob a inspiração da esfera pública habermasiana. De outro lado, o conjunto de pesquisadores que pretendia mover-se de maneira alternativa àquele setor hegemônico buscou, sobretudo, investigar quem e como a participação institucional mobilizava uma sociedade civil heterogênea, mais ou menos conectada à sociedade política. Faltava, portanto, ao próprio governo, um think tank exclusivo,

${ }^{6}$ Ver especialmente Pires (2011). 
preocupado com temas ligados à produção de governabilidade por meio das IMPI. A equipe da DIEST ocupou este lugar.

Ao longo deste período, foi-se afirmando, sobretudo no campo governamental, o Sistema e a Política Nacional de Participação Social, voltados, por um lado, para a articulação das IMPI e a produção de políticas não-contraditórias entre si, e por outro lado, com uma proposta clara de implementação da ideia de participação social como "método de governo".

\footnotetext{
Começamos a entender que, no caso da participação, nós tínhamos que trabalhar com estas duas ideias: construir um conjunto de diretrizes, de orientações para implementação das políticas de ações de participação institucional e uma proposta de articular tudo isso num sistema que seria uma espécie de arranjo. (Pedro Pontual, in Gurza Lavalle e Szwako, 2014, p. 101-2)
}

Entre meados de 2012 e de 2013 foi-se estruturando, de maneira paralela ao amadurecimento da proposta do Sistema e da Política Nacional de Participação Social, reuniões com representantes dos governos estaduais, municipais e do Distrito Federal, no sentido de tornar operativa nos entes federativos a visão de que a participação institucional, sob o lema da "participação como método de governo" é um caminho para a democratização das decisões sobre políticas públicas. O que se produziu foi um proto-instrumento de adesão à PNPS sob a forma de um Compromisso Nacional pela Participação Social, aberto à adesão de estados e municípios mediante a apresentação de um plano de ação para o setor.

Este esforço governamental se configurou no decreto presidencial n. 8243, datado de 23 de maio de 2014, que instituía a PNPS e o SNPS. Em síntese, o decreto conceitua as seguintes IMPI: conselho de políticas públicas, comissão de políticas públicas, conferência nacional, ouvidoria pública federal, mesa de diálogo, fórum interconselhos, audiência pública, consultas públicas e ambiente virtual de participação social, além de instituir um 
conceito de sociedade civil aplicável à PNPS e ao SNPS7 . Além disso, indica no parágrafo único de seu artigo $1^{\circ}$ que "na formulação, na execução, no monitoramento e na avaliação de programas e políticas públicas e no aprimoramento da gestão pública serão considerados os objetivos e as diretrizes da PNPS"8.

Mais especificamente sobre o SNPS, o decreto indica que este se comporia por "instâncias e mecanismos integradas

7 “O cidadão, os coletivos, os movimentos sociais institucionalizados ou não institucionalizados, suas redes e suas organizações". Artigo 2, inciso i.

${ }^{8}$ Por sua vez, as diretrizes e os objetivos da PNPS são os seguintes. Diretrizes: i) reconhecimento da participação social como direito do cidadão e expressão de sua autonomia; ii) complementaridade, transversalidade e integração entre mecanismos e instâncias da democracia representativa, participativa e direta; iii) solidariedade, cooperação e respeito à diversidade de etnia, raça, cultura, geração, origem, sexo, orientação sexual, religião e condição social, econômica ou de deficiência, para a construção de valores de cidadania e de inclusão social; iv) direito à informação, à transparência e ao controle social nas ações públicas, com uso de linguagem simples e objetiva, consideradas as características e o idioma da população a que se dirige; v) valorização da educação para a cidadania ativa; vi) autonomia, livre funcionamento e independência das organizações da sociedade civil; e vi) ampliação dos mecanismos de controle social. Objetivos: i) consolidar a participação social como método de governo; ii) promover a articulação das instâncias e dos mecanismos de participação social; iii) aprimorar a relação do governo federal com a sociedade civil, respeitando a autonomia das partes; iv) promover e consolidar a adoção de mecanismos de participação social nas políticas e programas do governo federal; v) desenvolver mecanismos de participação social nas etapas do ciclo de planejamento e orçamento; vi) incentivar o uso e o desenvolvimento de metodologias que incorporem múltiplas formas de expressão e linguagem de participação social, por meio da internet, com a adoção de tecnologias livres de comunicação e informação, especialmente, softwares e aplicações, tais como códigos fonte livres e auditáveis, ou os disponíveis no Portal do Software Público Brasileiro; vii) desenvolver mecanismos de participação social acessíveis aos grupos sociais historicamente excluídos e aos vulneráveis; viii) incentivar e promover ações e programas de apoio institucional, formação e qualificação em participação social para agentes públicos e sociedade civil; e ix) incentivar a participação social nos entes federados.

Idéias - Rev. Inst. Filos. Ciênc. Hum. UNICAMP, v.6, n.2, p. 35-58, jul/dez. 2015 
permanentemente em rede, de modo flexível, não hierarquizado e complementar", sendo que o decreto de modo geral é bastante lacônico ao se referir às articulações entre as IMPI. A não ser no artigo $10^{\circ}$, referente aos conselhos, em que se indica que estes deverão acompanhar "processos conferenciais relativos ao tema de sua competência"; ou, no caso das conferências, onde se indica como diretriz a "integração entre etapas municipais, estaduais, regionais, distrital e nacional" (artigo 12, inciso iv); pouco se avançou quanto à articulação entre as instâncias e mecanismos de participação. Como um decreto presidencial se aplica apenas às ações do próprio Executivo federal, apenas indica-se como um dos objetivos da PNPS o "incentivo à participação social nos entes federados". Ao que parece, a proposta do governo seria de uma atuação mais focada em mecanismos de indução a ações e marcos legais semelhantes nos estados e municípios, mas em uma estratégia que seria desenvolvida posteriormente.

QUADRO 1 - Definição das instâncias e mecanismos de participação institucional segundo o Decreto n. 8.243, de 23 de maio de 2014, que institui a Política Nacional de Participação Social e o Sistema Nacional de Participação Social

\begin{tabular}{|l|l|}
\hline IMPI & DEFINIÇÃO \\
\hline $\begin{array}{l}\text { conselho de políticas } \\
\text { públicas }\end{array}$ & $\begin{array}{l}\text { instância colegiada temática permanente, instituída } \\
\text { por ato normativo, de diálogo entre a sociedade } \\
\text { civil e o governo para promover a participação no } \\
\text { processo decisório e na gestão de políticas públicas }\end{array}$ \\
\hline $\begin{array}{l}\text { comissão de políticas } \\
\text { públicas }\end{array}$ & $\begin{array}{l}\text { instância colegiada temática, instituída por ato } \\
\text { normativo, criada para o diálogo entre a sociedade } \\
\text { civile o governo em torno de objetivo específico, com } \\
\text { prazo de funcionamento vinculado ao cumprimento } \\
\text { de suas finalidades }\end{array}$ \\
\hline
\end{tabular}




\begin{tabular}{|c|c|}
\hline conferência nacional & $\begin{array}{l}\text { instância periódica de debate, de formulação e de } \\
\text { avaliação sobre temas específicos e de interesse } \\
\text { público, com a participação de representantes do } \\
\text { governo e da sociedade civil, podendo contemplar } \\
\text { etapas estaduais, distrital, municipais ou regionais, } \\
\text { para propor diretrizes e ações acerca do tema tratado }\end{array}$ \\
\hline $\begin{array}{l}\text { ouvidoria pública } \\
\text { federal }\end{array}$ & $\begin{array}{l}\text { instância de controle e participação social } \\
\text { responsável pelo tratamento das reclamações, } \\
\text { solicitações, denúncias, sugestões e elogios relativos } \\
\text { às políticas e aos serviços públicos, prestados } \\
\text { sob qualquer forma ou regime, com vistas ao } \\
\text { aprimoramento da gestão pública }\end{array}$ \\
\hline mesa de diálogo & $\begin{array}{l}\text { mecanismo de debate e de negociação com a } \\
\text { participação dos setores da sociedade civil e do } \\
\text { governo diretamente envolvidos no intuito de } \\
\text { prevenir, mediar e solucionar conflitos sociais }\end{array}$ \\
\hline fórum interconselhos & $\begin{array}{l}\text { mecanismo para o diálogo entre representantes dos } \\
\text { conselhose comissões de políticas públicas, nointuito } \\
\text { de acompanhar as políticas públicas e os programas } \\
\text { governamentais, formulando recomendações para } \\
\text { aprimorar sua intersetorialidade e transversalidade }\end{array}$ \\
\hline audiência pública & $\begin{array}{l}\text { mecanismo participativo de caráter presencial, } \\
\text { consultivo, aberto a qualquer interessado, com a } \\
\text { possibilidade de manifestação oral dos participantes, } \\
\text { cujo objetivo é subsidiar decisões governamentais }\end{array}$ \\
\hline consulta pública & $\begin{array}{l}\text { mecanismo participativo, a se realizar em prazo } \\
\text { definido, de caráter consultivo, aberto a qualquer } \\
\text { interessado, que visa a receber contribuições por } \\
\text { escrito da sociedade civil sobre determinado } \\
\text { assunto, na forma definida no seu ato de convocação }\end{array}$ \\
\hline $\begin{array}{l}\text { ambiente virtual de } \\
\text { participação social }\end{array}$ & $\begin{array}{l}\text { mecanismo de interação social que utiliza } \\
\text { tecnologias de informação e de comunicação, em } \\
\text { especial a internet, para promover o diálogo entre } \\
\text { administração pública federal e sociedade civil }\end{array}$ \\
\hline
\end{tabular}

Fonte: Decreto 8.243/14. Elaboração do autor. 
O decreto presidencial n. 8.243, no entanto, foi severamente criticado por setores conservadores da mídia e em quase todo o Congresso Nacional. Todos os partidos políticos, à exceção do PT e do PCdoB se colocaram críticos à PNPS. Este posicionamento deve ser localizado no contexto da disputa eleitoral de outubro de 2014. Seu centro estava na acusação de uma suposta usurpação das funções do Congresso Nacional como órgão deliberativo sobre as ações governamentais e de fiscalização do Executivo. De outro lado, parte dos que se opuseram ao decreto - e, inclusive, o derrubaram com um decreto legislativo - dizem fazê-lo não por seu mérito, mas pela forma (decreto presidencial) como foi proposto, sem que tenha sido pela forma de projeto de lei do Executivo a ser encaminhado ao escrutínio do Congresso Nacional9. Até o momento, não há novidades na tramitação de alternativas ao decreto.

\section{5 - Por um olhar sobre a implementação da participação institucional}

Fracassou a tentativa do governo federal de estabelecer um novo marco legal para a participação institucional no Brasil. Por maiores que fossem seus limites, esta se constituiu em uma aposta para normatizar a existência das instâncias e mecanismos de participação institucional, ampliar a padronização de seus formatos e ações, diminuir as incongruências entre elas. Ou seja, estabelecer parâmetros para sua implementação.

O campo de estudos sobre implementação de políticas públicas tem contribuído sobremaneira para a ampliação do conhecimento gerado sobre os fatores de sucesso em políticas públicas. Para além da visão de que a decisão em níveis políticos superiores é neutra e burocraticamente assimilada pelos níveis inferiores da administração pública, a literatura da implementação

\footnotetext{
9 Estão em elaboração iniciativas legislativas no âmbito da Câmara dos Deputados, de maneira que este tema deve retornar à pauta política em breve.
} 
vem retomando espaço nos estudos sobre a policy (BARRET, 2004; LOTTA, 2012), de modo a indicar a necessidade de conhecimento sobre os meandros da administração pública e o papel do burocrata na compreensão sobre seus fatores de sucesso.

A disseminação das instâncias e mecanismos de participação institucional em quase todos os setores de políticas públicas, em todos os níveis da federação, no interior de equipamentos de saúde, educação, cultura, meio ambiente etc., tem sido realizada de maneira pouco padronizada, pouco articulada, quase passando ao largo de estruturas de controle interno dos governos. Esta frouxidão mais ou menos generalizada na implementação destas IMPI - há exceções, sem dúvida - tem sido a justificativa apresentada pelo repúdio ou desinteresse para com elas, por parte daqueles que as desconsideram como constitutivas dos esforços de aprofundamento e aperfeiçoamento da democracia no país. $\mathrm{O}$ Sistema e a Política Nacional de Participação Social buscava, ainda que de maneira limitada, alterar esta situação.

Os desenhos institucionais das IMPI foram fortemente avaliados pela literatura ao longo da segunda metade da década de 1990 e nos anos 2000. A questão da efetividade - ou seja, a preocupação com os impactos das IMPI - foi fortemente incorporada a este campo de estudos no período recente. Muito se teorizou sobre a capacidade destes espaços em possibilitarem voz e poder aos representantes da sociedade civil.

Há, no entanto, um vazio quanto aos estudos sobre a implementação destas IMPI. Pouco se sabe sobre que fatores podem tornar uma ou outra instância, um ou outro mecanismo mais eficaz, pois pouco se sabe sobre como os diversos contextos institucionais atuam para fortalecê-los ou enfraquecê-los. Pouco se sabe sobre a importância do perfil e da conduta dos burocratas/ gestores que lideram estas instâncias, e qual seu impacto sobre o sucesso ou fracasso das experiências. Pouco se sabe, ainda, sobre o quanto a estrutura de articulação interna aos governos e as instâncias e mecanismos de participação são relevantes para sua sustentação política e sua efetividade. Ainda temos dificuldade em tematizar o próprio sentido político das dificuldades da 
Reflexões sobre as dificuldades de implementação...

implementação das IMPI, considerando que se trata de uma questão de compartilhamento de poder e, portanto, de diminuição de poder daqueles que os possuem.

Compreendemos que um programa de pesquisas que se debruce sobre estas perguntas - todas elas relacionadas a variáveis relativas sobre como se implementa uma política de participação - podem nos propiciar respostas sobre os fundamentos políticos e administrativos da participação institucional, suas lacunas e potencialidades, de modo que se possa, para além de uma compreensão mais acurada desse fenômeno político, colaborar para melhorar nossa democracia.

\section{Bibliografia}

ABRUCIO, F. Os Barões da Federação. Lua Nova, n. 33, p. 165-83, 1994.

ARRETCHE, M. Políticas sociais no Brasil: descentralização em um Estado federativo. Revista Brasileira de Ciências Sociais, v. 14, n. 40, junho, 1999.

AVRITZER, L. A moralidade da democracia: ensaios em teoria habermasiana e teoria democrática. São Paulo: Perspectiva; Belo Horizonte: UFMG, 1996.

AVRITZER, L.; NAVARRO, Z. (orgs.) A inovação democrática no Brasil: o orçamento participativo. São Paulo: Cortez, 2003.

BARRETT, S. M. Implementation studies: time for a revival? Personal reflections on 20 years of implementation studies. Public Administration, v. 82, n. 2, p. 249-262, Jun. 2004.

DAGNINO, E. (org.). Sociedade civil e espaços públicos no Brasil. São Paulo: Paz e Terra, Unicamp, 2002.

DOWBOR, M. Da inflexão pré-constitucional ao SUS municipalizado. Lua Nova, n. 78, p. 158-222, 2009. 
GURZA LAVALLE, A.; SZWAKO, J. Origens da política nacional de participação social: entrevista com Pedro Pontual. Novos Estudos, n. 99, julho, 2014, p. 91-104.

LESSA, R. A Constituição brasileira de 1988 como experimento de filosofia pública: um ensaio. In: OLIVEN, R. G.; RIDENTI, M.; BRANDÃO, G. M. (orgs.). A Constituição de 1988 na vida brasileira. São Paulo: Hucitec, ANPOCS, 2008.

LOTTA, G. O papel das burocracias do nível de rua na implementação de políticas públicas: entre o controle e a discricionariedade. In: FARIA, C. A. P. (org.). Implementação de políticas públicas: teoria e prática. Belo Horizonte: PUC MG, 2012, p. 20-49.

MOURA, S. Ideário e prática da participação popular no governo local: a experiência de Porto Alegre. In: FISCHER, T. (org.) Poder local: governo e cidadania, Rio de Janeiro: Fundação Getúlio Vargas, 1993.

NEVES, A. Cultura política e democracia participativa: um estudo sobre o orçamento participativo. Rio de Janeiro: Gramma, Faperj, 2008.

PIRES, R. (org.). Efetividade das instituições participativas no Brasil: estratégias de avaliação. Brasília: IPEA, 2011.

ROMÃO, W. PB for what? The political meaning of participatory budgeting. XXXII Congress of the Latin American Studies Association, Chicago, IL, May 21-24, 2014.

SOUZA, C.; PIRES, R. Conferências nacionais como interfaces socioestatais: seus usos e papeis na perspectiva de gestores federais. Revista do Serviço Público. Brasília, n. 63, v. 3, p. 499518, out. dez, 2012.

SZWAKO, J. Participar vale a pena, mas...: a democracia participativa brasileira vista pelas lentes da utopia. In: SOUTO, A. L.; PAZ, R. D. (orgs.). Novas lentes sobre a participação: utopias, agendas e desafios. São Paulo: Instituto Pólis, 2012. 
Reflexões sobre as dificuldades de implementação...

TATAGIBA, L. Os conselhos gestores e a democratização das políticas públicas no Brasil. In: DAGNINO, E. (org.). Sociedade civil e espaços públicos no Brasil. São Paulo: Paz e Terra, Unicamp, 2002.

TATAGIBA, L.; BLIKSTAD, K. “Como se fosse uma eleição para vereador": dinâmicas participativas e disputas partidárias na cidade de São Paulo. Lua Nova, n. 78, p. 175-217, 2011.

ABERS, R.; SERAFIM, L.; TATAGIBA, L. Repertórios de interação estado-sociedade em um estado heterogêneo: a experiência na era Lula. Dados, v. 57, p. 325-357, 2014.

VRIES, M. S. de. (2000). The bureaucratization of participation. International Review of Administrative Sciences, n. 66, p. 325-348. 